\title{
Enfermedad de Kawasaki asociada a infección por Dengue: reporte de un caso
}

\author{
Kawasaki disease associated with Dengue infection: case report \\ Doença de Kawasaki associada à dengue: Um relato de caso
Jonathan Marcos Chusin Montesdeoca (1) ', María Andrea Mosquera Salazar (1) ', Jimmy Mauricio Barreiro Casanova (id ${ }^{2}$, Johanna Priscila Duque López $\mathbb{B}^{3}$

\begin{abstract}
1 Servicio de Pediatría, Hospital de Niños Roberto Gilbert Elizalde, Guayaquil-Ecuador; 2 Área de Emergencia, Hospital de Niños Roberto Gilbert Elizalde, GuayaquilEcuador; ${ }^{3}$ PROSIGMA S.A, QuitoEcuador.
\end{abstract}

Correspondencia a: Jonathan Marcos Chusin Montesdeoca, marcos141092@ gmail.com

Recibido: 26 de junio, 2021

Aceptado: 10 de septiembre, 2021 Publicado: 18 de noviembre, 2021

\section{CASO CLÍNICO}

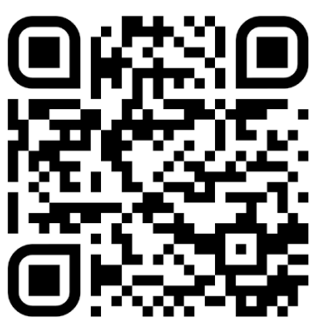

Escanea en tu dispositivo móvil o revisa este artículo en:

https://revistaclinicaguayaquil.org

\section{RESUMEN}

El dengue es una virosis común en Latinoamérica, de la cual pueden derivar múltiples complicaciones, las más comunes asociadas a la disfunción endotelial propia de la fisiopatología de esta enfermedad. Sin embargo, es limitada la literatura sobre las complicaciones asociadas a vasculitis, como es el caso de la enfermedad de Kawasaki, de la cual aún se desconoce su causa, sospechándose en infecciones virales como gatillantes de la reacción hiperinmune y, de entre los cuales, la literatura reciente describe una asociación con el virus del SarsCov2, responsable de la actual pandemia. Se reporta un caso de enfermedad de Kawasaki asociada a infección por Dengue, que fue tratado en un hospital de la ciudad de Guayaquil - Ecuador, durante los meses en los que esta ciudad se encontraba severamente afectada por la pandemia de COVID-19.

Palabras clave: Dengue; Enfermedad de Kawasaki; Pediatría; Vasculitis

\begin{abstract}
Dengue is a common virus in Latin America, from which multiple complications may arise, the most common associated with endothelial dysfunction characteristic of the pathophysiology of this disease. However, there is limited literature on complications associated with vasculitis, as is the case of Kawasaki disease, whose cause is still unknown, suspecting viral infections as triggers of hyperimmune reaction, and among which, recent literature describes an association with the SarsCov2 virus, responsible for the current pandemic. We report a case of Kawasaki disease associated with Dengue infection, which was treated in a hospital in the city of Guayaquil - Ecuador, during the months in which this city was severely affected by the COVID19 pandemic.
\end{abstract}

Key words: Dengue; Kawasaki disease; Pediatrics; Vasculitis

\section{RESUMO}

A dengue é um vírus comum na América Latina, do qual podem surgir múltiplas complicações, as mais comuns das quais estão associadas à disfunção endotelial típica da fisiopatologia desta doença. No entanto, a literatura sobre complicações associadas à vasculite é limitada, como é o caso da doença de Kawasaki, cuja causa ainda é desconhecida, sendo as infecções virais suspeitas como desencadeantes da reação hiperimune, entre as quais a literatura recente descreve uma associação com o vírus SarsCov2, responsável 
pela atual pandemia. Relatamos um caso de doença de Kawasaki associada à dengue, que foi tratada em um hospital na cidade de Guayaquil, Equador, durante os meses em que esta cidade foi severamente afetada pela pandemia COVID19.

Palavras-chave: Dengue; Doença de Kawasaki; Pediatria; Vasculite

\section{INTRODUCCIÓN}

El dengue es una enfermedad causada por un arbovirus, del cual se conocen 4 serotipos, es transmitida principalmente por la picadura del artrópodo Aedes aegypti (1,2). En Ecuador en el 2020 se reportaron 16570 casos, con una incidencia de 98.26/100.000 habitantes, 6 fallecidos, con unatasa de letalidad del $0.036 \%$, afectando mayoritariamente al grupo etario entre 20 y 49 años, seguido de los grupos entre 5 a 9 años en segundo lugar, el de 10 a 14 años en tercer lugar (1).

Tras la picadura del mosquito existe un periodo de incubación que varía entre 4 a 6 días, seguido de las 3 fases propias de la enfermedad: fase febril con duración de 3 a 7 días, durante la cual se produce la viremia, caracterizada por fiebre, cefalea, vómitos, mialgia, artralgia y rash transitorio; la fase crítica, que inicia el momento de la defervescencia, dura entre 24 a 48 horas, en las cuales se pueden producir sus complicaciones potencialmente mortales; la gran mayoría de pacientes pasa de la fase febril directamente a la tercera fase o fase de recuperación, que dura 2 a 4 días, incluso hasta semanas, durante las cuales se resuelve la fuga plasmática, se estabilizan los signos vitales y puede reaparecer un nuevo rash particularmente pruriginoso (2).

Las complicaciones se producen durante la fase crítica, entre ellas se encuentran el choque por extravasación del plasma, hemorragias graves y el compromiso orgánico (2). Sin embargo, literatura extranjera ha descrito a la enfermedad de Kawasaki como complicación de esta infección; como lo describen Philip, Ahamed y Singh en el 2018, de un total de 65 casos estudiados en India en 4 años, 48 fueron estudiados con serología para dengue y el $18.7 \%$ tuvieron resultado positivo (3). Una explicación a esa asociación es que la infección viral también induce proliferación celular y cambios morfológicos en las células endoteliales, lo que potencialmente puede causar arteritis, incluyendo arteritis coronaria, lo cual es característico de la enfermedad de Kawasaki. Se describe además que, en la población estudiada, la mayor proporción de pacientes tenía más de 5 años, distinto a lo clásicamente descrito como grupo etario más común, entre 6 meses a 5 años (3).

Por lo poco común que es la asociación entre enfermedad de Kawasaki y el dengue, se presenta el siguiente caso clínico de una paciente con clínica y serología positivas para infección por dengue y que, durante su evolución, cumplió con criterios de enfermedad de Kawasaki.

\section{DESCRIPCIÓN DEL CASO CLÍNICO}

Paciente femenina de 7 años sin antecedentes patológicos, con cuadro clínico de 24 horas de evolución con cefalea holocraneana (EVA 7/10), mialgias, fiebre que no cede a paracetamol y dolor abdominal difuso (EVA 5/10). Llega febril, con exantema generalizado, conjuntivitis no exudativa, labios rojos y fisurados, edema de palmas y plantas.

Inicialmente abordada como dengue con signos de alarma, se realizó manejo con cristaloides según guías de la OPS 2015 y antitérmicos. Los estudios de laboratorio reportaron Antígeno NS1, IgG e IgM para dengue positivos, biometría hemática con trombocitopenia, sin leucopenia ni hemoconcentración, PCR elevada y examen general de orina con piuria estéril. La madre indicó contacto reciente con persona con IgM positiva para SarsCov2, en el contexto de la pandemia por este virus durante el 2020, se realizaron estudios para descartar Síndrome Inflamatorio Multisistémico Pediátrico asociado a infección por SarsCov2 concomitante, marcadores inflamatorios con PNA (131 pg/ml), Dímero D (0.6ug/ml), Troponina T (3.59ng/ml), LDH (262U/L) resultaron elevados, sin embargo, la serología y PCR SarsCov2 en hisopado nasofaríngeo realizados a las 24 horas y a los 8 días de evolución, resultaron negativos.

En el transcurso del primer día hospitalización se solicitó un ecocardiograma que reportó derrame pericárdico mínimo, sin repercusión hemodinámica, indicándose manejo expectante y control en 48 horas, permaneciendo hospitalizada con manejo sintomático. Durante su observación persiste taquicárdica pese al control térmico. En el ecocardiograma de control a las 48 horas se reportó un aneurisma de la arteria coronaria derecha de $4 \mathrm{~mm}(\mathrm{Z}:+3.5)$ y leve derrame pericárdico sin repercusión hemodinámica; se integra el diagnóstico de enfermedad Kawasaki-like, indicándose dosis de inmunoglobulina humana intravenosa y se 
difiere el uso de aspirina por la trombopenia presentada. A pesar de esto, persistían los picos febriles y tras 48 horas adicionales, completando 5 días de fiebre, reunió todos los criterios de enfermedad de Kawasaki, indicándose una segunda dosis de inmunoglobulinas, junto con 3 pulsos diarios de corticoide intravenoso, con lo que la fiebre cedió, evidenciándose mejoría clínica.

Al octavo día de hospitalización se realizó nuevo ecocardiograma de control, que no reportó las anomalías indicadas anteriormente. Tras 9 días de hospitalización paciente egresa asintomática con corticoides, antiplaquetario y heparina de bajo peso molecular para manejo ambulatorio.

\section{DISCUSIÓN}

Se desconoce la etiología exacta de la enfermedad de Kawasaki; sin embargo, se han descrito múltiples asociaciones a procesos infecciosos, incluyendo la infección por los virus del dengue (3) y del SarsCov2 a propósito de la pandemia por este último (4). Se describe que el grupo etario más común se ubica entre los 6 meses y los 5 años, así mismo que pacientes fuera de este rango, se asocian a mayores complicaciones cardiovasculares, como en el caso de nuestra paciente (5). Por otro lado, es limitada la evidencia sobre su asociación con la infección por el virus del dengue. Reportes de casos registrados en India, mencionan esta asociación, destacándose que los pacientes con serología positiva para dengue y clínica típica de enfermedad de Kawasaki, superaban los 5 años de edad, además de describir una posible asociación entre la piuria estéril y un riesgo aumentado de daño coronario (3), hallazgo también registrado en nuestro caso.

Dentro del diagnóstico diferencial se consideró la posibilidad de un síndrome inflamatorio multisistémico pediátrico asociado a la infección por SarsCov2 dado el nexo epidemiológico de la paciente con un caso positivo, dentro de su abordaje inicial se incluyó marcadores inflamatorios cardiacos, cuyos resultados altos direccionaron a un estudio ecocardiográfico inicial que determinó el derrame incipiente a las 24 horas, con aneurisma coronario tras 48 horas; sin embargo, la serología y PCR SarsCov2 en hisopado nasofaríngeo realizados a las 24 horas y 8 días de evolución, resultaron negativos, descartándose la infección. Fue necesario la administración de inmunoglobulinas humanas en 2 ocasiones ya que se registró persistencia de la sintomatología, similar a lo registrado por
Agarwal, Shah y Gupta en su reporte de caso clínico en el 2016 en una niña de 5 años en la India (6).

Aunque se desconoce la etiología exacta de la enfermedad de Kawasaki, esta se debe sospechar en casos de pacientes con criterios de la misma que cursen procesos infecciosos, incluyendo la infección por virus del dengue, como en el presente caso.

\section{REFERENCIAS BIBLIOGRÁFICAS}

1. Ministerio de Salud Pública. Subsistema de vigilancia SIVE- alerta enfermedades transmitidas por vectores Ecuador, SE 01 - 52 - 2020 [Internet]. Gob.ec. [citado 2021 Jun 26]. Disponible en: https:// www.salud.gob.ec/wp-content/uploads/2021/01/ Vectores-SE-52.pdf

2. Organizacion Panamericana de la Salud. Dengue: guías para la atención de enfermos en la región de las Américas. 2nd ed. OPS; 2016.

3. Philip S, Ahamed Z, Singh S. An Update on Kawasaki Disease Indian Perspective. Austin Cardio \& Cardiovasc Case Rep. 2018;3(2):1023.

4. Minchala-Urgilés RE, Ramírez-Coronel AA, Encalada-Parapi BJ, Caceres SG, de los Ángeles Estrella-González M, Minchala-Urgilés ME, et al. Enfermedad de Kawasaki asociada a COVID-19: Revisión Sistemática. Archivos Venezolanos de Farmacología y Terapéutica. 2020;39(8):935-940. DOI: $10.5281 /$ zenodo.4543438

5. Sánchez-Manubens J. Enfermedad de Kawasaki. Protoc diagn ter pediatr. 2020;2:213-224.

6. Agarwal E, Shah D, Gupta P. Dengue fever triggering Kawasaki disease. Indian Pediatr. 2017;54(1):51-2. DOI: 10.1007/s13312-017-0997-

\section{ACERCA DE LOS AUTORES}

1. Jonathan Marcos Chusin Montesdeoca. Servicio de Pediatría, Hospital de Niños Roberto Gilbert Elizalde, GuayaquilEcuador.

\section{ORCID: 0000-0001-8816-5392}

2. María Andrea Mosquera Salazar. Servicio de Pediatría, Hospital de Niños Roberto Gilbert Elizalde, Guayaquil- Ecuador.

ORCID: 0000-0003-1105-8526

3. Jimmy Mauricio Barreiro Casanova. Área de Emergencia, Hospital de Niños Roberto Gilbert Elizalde, Guayaquil- Ecuador.

ORCID: 0000-0001-5392-159X

4. Johanna Priscila Duque López. PROSIGMA S.A, Quito-Ecuador.

ORCID: 0000-0002-3813-2231 